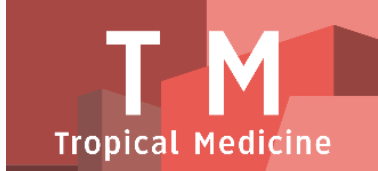

PAPER - OPEN ACCESS

Efek Pemberian Ekstrak Etanol Daun Dan Batang Ubi Jalar Ungu (Ipomoea batatas L.) Terhadap Penurunan Kadar Glukosa Darah Pada Tikus Jantan Galur Wistar Yang Diinduksi Aloksan
Author
: Haryoto
DOI
: 10.32734/tm.v1i3.279
Electronic ISSN
: 2623-0542
Print ISSN
: 2623-0550

Volume 1 Issue 3-2018 TALENTA Conference Series: Tropical Medicine (TM)

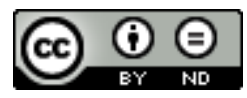

This work is licensed under a Creative Commons Attribution-NoDerivatives 4.0 International License.

Published under licence by TALENTA Publisher, Universitas Sumatera Utara
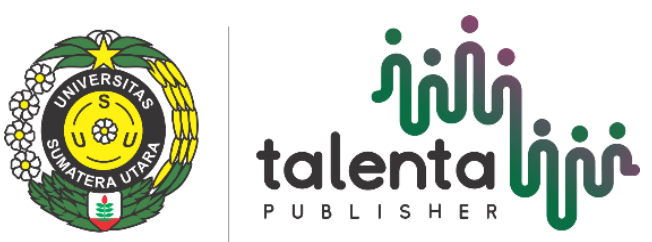


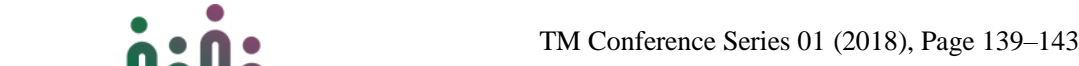

\section{Efek Pemberian Ekstrak Etanol Daun Dan Batang Ubi Jalar Ungu (Ipomoea batatas L.) Terhadap Penurunan Kadar Glukosa Darah Pada Tikus Jantan Galur Wistar Yang Diinduksi Aloksan}

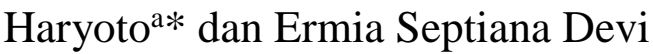 \\ ${ }^{a}$ Fakultas Farmasi, Universitas Muhammadiyah Surakarta
}

haryoto@ums.ac.id

\begin{abstract}
Abstrak
Tanaman ubi jalar ungu (Ipomoea batatas L.) mudah didapat dan banyak kegunaannya,terutama bagian umbi ubi jalar ungu yang banyak diolah masyarakat sedangkan bagian daun dan batang pemanfaatnya belum maksimal. Umbinya telah diketahui mempunyai aktivitas dapat menurunkan kadar gula darah. Penelitian ini bertujuan untuk mengetahui efek penurunan kadar glukosa darah dari ekstrak etanol daun dan batang ubi jalar ungu serta golongan senyawa yang terkandung dalam ekstrak. Desain penelitian menggunakan randomized pre-test post-test kontrol grup desain. Pada penelitian ini menggunakan 15 ekor tikus jantan galur wistar dan dibagi menjadi 5 kelompok yaitu kontrol negatif (akuades), kontrol positif (metformin $45 \mathrm{mg} / \mathrm{kgBB}$ ), kelompok perlakuan ubi jalar ungu dosis 150; 300; $600 \mathrm{mg} / \mathrm{kgBB}$, sebelumnya masing masing tikus dinduksi dengan aloksan $150 \mathrm{mg} / \mathrm{kgBB}$, dan dilakukan pemantauan selama 14 hari. Pemeriksaan kadar gula darah menggunakan spektrofotometer visibel dengan panjang gelombang $500 \mathrm{~nm}$. Data dianalisis secara statistik untuk mengetahui perubahan kadar gula darah. Hasil yang didapat dengan pemberian ekstrak pada dosis 150,300, dan $600 \mathrm{mg} / \mathrm{kgBB}$ selama pemantauan 14 hari dapat menurunkan kadar gula darah berturut - turut menjadi $96,33 \pm 4,72 ; 66,67 \pm 16,16$; dan 142,67 $\pm 27,06 \mathrm{mg} / \mathrm{dL}$. Ekstrak etanol daun dan batang ubi jalar ungu memiliki kandungan senyawa yaitu alkaloid, flavonoid, saponin, tanin dan senyawa fenolik.
\end{abstract}

Kata kunci : Diabetes melitus, Ipomoea batatas L, aloksan, galur wistar

\begin{abstract}
Purple sweet potato (Ipomoea batatas L.) is a plant that is easy to obtain and has many beneficiaries, especially the purple sweet potato tubers that had been commonly used whileits leaves and stems of beneficiaries is not yet maximized. Purple sweet potato tubers have been known to have activity that can lower blood sugar levels. This study aims to determine the effect of the ethanol extract of the leaves and stems of purple sweet potato and classes of compounds contained in the extract in lowering blood glucose level.The research design used in this research is randomized pre-test post-test control group design. This researchused 15 Wistar male rats strain that were divided into 5 groups that includes: negative control (distilled water), positive control (metformin $45 \mathrm{mg} / \mathrm{kgBB}$ ), the dose of $150 \mathrm{mg} / \mathrm{kgBB}$, the dose of $300 \mathrm{mg} / \mathrm{kgBB}$, doses 600 $\mathrm{mg} / \mathrm{kgBB}$, each rat was being induced byalloxan as diabetogenic agent and being monitored for 14 days. The examination of blood sugar levels was conducted using a visible spectrophotometer with $500 \mathrm{~nm}$ wavelength. The collected data were statistically analyzed to determine changes in blood sugar levels. The results obtained by giving the extracts at a dose of 150,300 , and $600 \mathrm{mg} / \mathrm{kg}$ throughout the 14 days of monitoring process proved that it can lower blood sugar levels as follows; $96.33 \pm 4.72 ; 66,67 \pm 16.16 ; 142.67 \pm 27.06 \mathrm{mg} / \mathrm{dL}$. The ethanol extract of the leaves and stems of the purple sweet potato contains the alkaloid compounds that include: flavonoids, saponins, tannins and phenolic compounds.
\end{abstract}

Keywords: Diabetes mellitus, Ipomoea batatas L, alloxan, Wistar strain

\section{Pendahuluan}

Penderita diabetes mellitus (DM) tingkat prevalensi global tahun 2015 berjumlah 415 juta $(8,8 \%)$ dan diperkirakan akan mengalami peningkatan menjadi 642 juta $(10,4 \%)$ pada tahun 2040 dari populasi penduduk dunia yang menderita DM dengan umur 20-79 tahun. Sebanyak 5 juta orang meninggal dikarenakan terkena DM. Indonesia merupakan negara urutan ke-7 dengan kejadian diabetes mellitus dengan 10 juta penderita dan diperkirakan tahun 2040 menjadi urutan ke-6 dengan jumlah 16,2 juta dari populasi penduduk dunia [1]

Di Indonesia produksi ubi jalar hampir mencapai 90\% digunakan sebagai bahan pangan dengan tingkat konsumsi 6,6 $\mathrm{kg} / \mathrm{tahun}$. Ubi jalar mempunyai nilai indeks glikemik (IG) rendah sampai medium kisaran 54-68 dibandingkan dengan makanan yang menjadi sumber karbohidrat yaitu roti tawar, beras dan kentang, namun memiliki nilai IG yang lebih tinggi 
dibanding ubi kayu [2]. Ubi jalar dengan nilai indeks glikemik yang rendah dapat digunakan penderita diabetes karena tidak secara cepat meningkatkan kadar gula darah. Ubi jalar ungu tergolong relatif murah, mudah didapat, dan bagian dari tanaman ini dapat dimanfaatkan seperti umbi ubi jalar ungu yang dapat diolah menjadi selai, es krim, mie, keripik, dan stik ubi jalar [3].

Sedangkan daun dan batang ubi jalar ungu dimanfaatkan oleh masyarakat untuk sayuran dan bahan pakan ternak. Daun dan batang ubi jalar oleh masyarakat, dinilai mempunyai citra produk yang rendah karena tidak bernilai ekonomis tinggi, terutama daun dan batang ubi jalar ungu belum ada bukti ilmiah yang menunjukkan manfaat bagi penderita diabetes seperti umbi ubi jalar ungu yang mempunyai IG yang rendah.

Penelitian ini dimaksudkan untuk mengetahui efek pemberian ekstrak etanol daun dan batang ubi jalar ungu terhadap penurunan kadar glukosa darah pada tikus jantan galur wistar yang diinduksi aloksan dan uji kualitatif golongan senyawa kimia yang terkandung di dalam ekstrak etanol daun dan batang ubi jalar ungu. antidiabetes.

Hasil yang diperoleh diharapkan dapat melengkapi data ilmiah mengenai khasiat daun dan batang ubi jalar ungu sebagai

\section{Bahan dan Metode}

\subsection{Pembuatan ekstraketanol daun dan batang ubi jalar ungu}

a. Pembuatan ekstrak etanol daun dan batangubi jalar ungu

Daun dan batang tanaman ubi jalar ungu (Ipomoea batatas L.) yang telah diserbuk, ditimbang sebanyak 600 g ditambahkan etanol sebanyak 7 kali berat ekstrak simplisianya. Setelah 3x24 jam, dilakukan penyaringan maserat. Setelah itu, dilakukan remaserasi sebanyak 2 kali. Filtrat etanol yang didapat, dipekatkan menggunakan vacuum rotary evaporator.

\subsection{Uji antidiabetes}

Perlakuan hewan uji. Uji efek hipoglikemik dilakukan dengan mengaklimatisasi 15 ekor tikus putih jantan galur wistar selama seminggu lalu diukur kadar glukosa awal atau baseline yaitu antara $50-135 \mathrm{mg} / \mathrm{dL}$ [4]. Selanjutnya, tikus dengan kadar glukosa normal dan memenuhi kriteria inklusi digunakan untuk penelitian. Tahap selanjutnya, tikus dipuasakan terlebih dahulu selama 12-18 jam lalu masing- masing tikus dibuat diabetes dengan diinduksi aloksan dengan dosis $150 \mathrm{mg} / \mathrm{kgBB}$ berdasarkan hasil orientasi, aloksan dilarutkan dengan water for injection diberikan secara intraperitoneal lalu dilakukan pemeriksaan glukosa darah setelah diinduksi aloksan yang dilakukan pemantauan kadar gula darah selama 14 hari, tikus dengan kadar glukosa darah > $200 \mathrm{mg} / \mathrm{dL}$ dianggap sudah diabetes dan digunakan untuk penelitian.

Perlakuan tikus diabetes selama 14 hari. Tikus yang sudah diabetes dibagi secara acak ke dalam 5 kelompok perlakuan,setiap kelompok terdiri dari 3 tikus sebagai berikut :

Kelompok I: kontrol negatif akuades p.o

Kelompok II: kontrol positif diberi metformin dosis $45 \mathrm{mg} / \mathrm{kgBB}$

Kelompok III: diberi ekstrakdosis $150 \mathrm{mg} / \mathrm{kgBB}$

Kelompok IV: diberi ekstrak dosis $300 \mathrm{mg} / \mathrm{kgBB}$

Kelompok V: diberi ekstrak dosis $600 \mathrm{mg} / \mathrm{kgBB}$

Tiap kelompok diberi perlakuan secara peroral 1 kali sehari selama 14 hari dengan mengambil darah dari vena lateralis ekor sejumlah kurang lebih $1 \mathrm{~mL}$ volume darah. Selanjutnya, dilakukan sentrifuge selama 15 sampai 20 menit dengan kecepatan $13.400 \mathrm{rpm}$. Pengukuran kadar glukosa darah dengan metode enzimatik menghasilkan kuinonimin yang terbentuk berwarna merah dan ekivalen dengan glukosa sehingga warna yang terukur dari produk kuinonimin setara dengan kadar glukosa yang dapat terbaca pada panjang gelombang $500 \mathrm{~nm}$.

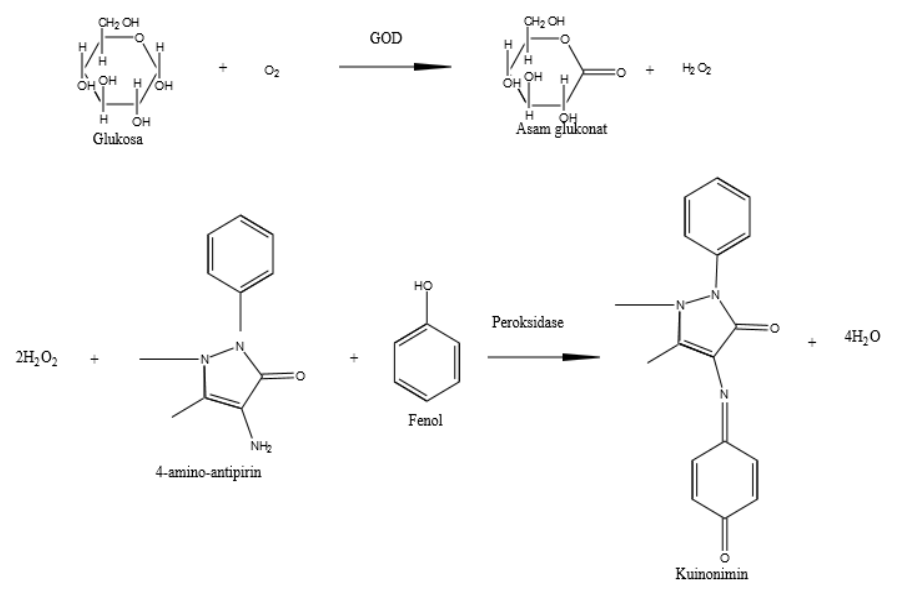

Gambar 1. Reaksi pada metode enzimatik kolorimetrik 


\subsection{Uji fitokimia}

Uji fitokimia senyawa dilakukan untuk mengidentifikasi golongan senyawa metabolit sekunder yang terkandung dalam ekstrak dengan menggunakan reagen kimia.

1. Alkaloid

Uji Wagner : Ekstrak ditambahkan $1 \mathrm{~mL}$ larutan KI membentuk endapan coklat kemerahan [5].

2. Flavonoid

Tes $\mathrm{NaOH} \quad$ :Ekstrak ditambahkan $0.5 \mathrm{~mL} \mathrm{NaOH}$ menunjukkan warna kuning [5].

3. Saponin

Ekstrak ditambah dengan air dan digojok kuat menghasilkan buih yang stabil selama 1 menit [6].

4. Tanin dan senyawa fenolik

Ekstrak ditambahkan $1 \mathrm{~mL}$ larutan $\mathrm{FeCl}_{3}$ menunjukkan warna hitam kehijauan [5].

\subsection{Analisis data}

Data hasil pemeriksaan kadar gula darah dari tiga titik yaitu kadar gula darah awal (baseline), hari ke-4 induksi aloksan, dan perlakuan akhir hari ke-14.Data yang didapat dari selisih kadar gula darah pada hari ke-14 dengan hari ke-4 setelah induksi aloksan. Selanjutnya dilakukan ujiSaphiro-Wilk dan Levene test untuk mengetahui normalitas dan homogenitas data. Setelah data diketahui terdistribusi normal dan homogen dilanjutkan dengan uji One way Anova dengan tingkat kepercayaan 95\% yang dilanjutkan dengan uji Post-Hoc LSD untuk mengetahui perbedaan yang bermakna minimal antara kelompok kontrol negatif, kontrol positif, kelompok dosis 1 (ekstrak etanol daun dan batang ubi jalar ungu $150 \mathrm{mg} / \mathrm{kgBB}$ ), kelompok dosis 2 (ekstrak etanol daun dan batang ubi jalar ungu $300 \mathrm{mg} / \mathrm{kgBB}$ ), dan kelompok dosis 3 (ekstrak etanol daun dan batang ubi jalar ungu 600 $\mathrm{mg} / \mathrm{kgBB}$ ).Semua data, dihitung menggunakan program SPSS 23.

\section{HASIL DAN PEMBAHASAN}

Determinasi tanaman bertujuan untuk mengetahui identitas tanaman yang sebenarnya dan dengan cara yang tepat dengan melihat kunci determinasi. Determinasi dilakukan di Laboratorium Biologi (FKIP) Universitas Muhammadiyah Surakarta dengan surat keterangan nomor 577/A.E-I/LAB.BIO/X/2016 menyatakan hasil determinasi tanaman ubi jalar ungu (Ipomoea batatas L.) .

Berdasarkan hasil determinasi tersebut dapat disimpulkan bahwa tanaman yang digunakan merupakan spesies Ipomoea batatas Lamk dengan deskripsi tanaman akar termasuk jenis perakaran tunggang dan serabut. Batang hijau bergetah, bentuk silindris, percabangan merambat tidak beraturan, daun berwarna hijau dan daun muda berwarna kemerahan, tulang daun menyirip, tekstur daun lunak, bunga terletak di ketiak daun, mahkota berbentuk lonceng, umbinya mempunyai warna putih, ungu, kuning, orange jingga, serta bagian biji berukuran bulat kecil dan berwarna hitam.Setelah mengetahui tanaman yang digunakan adalah benar tanaman ubi jalar selanjutnya dilakukan pembuatan ekstrak daun dan batang ubi jalar ungu.Sebelum tahap ekstraksi, dilakukan pembuatan simplisia.Simplisia daun dan batang ubi jalar ungu diekstraksi dengan penyari etanol $96 \%$ dengan menggunakan metode maserasi. Metode maserasi dipilih karena terdapat beberapa keuntungan yaitu metode mudah dilakukan, dan tepat digunakan untuk simplisia yang kemungkinan mudah menguap bila terkena panas atau tidak tahan pemanasan. Ekstraksi total dilakukan menggunakan penyari etanol untuk dapat mengekstrak sebanyak mungkin senyawa serta dapat meningkatkan permeabilitas dinding sel sehingga dapat menfasilitasi ekstraksi senyawa polar, semi polar ataupun senyawa dengan kepolaran yang rendah karena etanol bersifat netral, dan mempunyai daya absorbsi yang baik [7].

Proses ekstraksi dalam penelitian ini menggunakan penyari etanol dengan metode maserasi dan didapatkan ekstrak kental sebanyak 145,06g dengan rendemen ekstrak sebesar 22,81\% dari 635,88 g simplisia kering daun ubi jalar ungu. Setelah menjadi sediaan kental atau disebut ekstrak dengan warna hijau kehitaman, berbau khas, tekstur kental. Ekstrak tersebut digunakan untuk analisis kualitatif golongan senyawa alkaloid, flavonoid, saponin, tanin dan fenolik yang dilakukan dengan uji tabung.Analisis fitokimia bertujuan untuk mengetahui golongan senyawa dari ekstrak.Hasil kualitatif ditunjukkan dengan terbentuknya endapan dan perubahan warna yang terjadi.

Berdasarkan hasil pemeriksaan fitokimia senyawa ekstrak etanol daun dan batang ubi jalar ungu mengandung flavonoid, alkaloid, saponin, tanin dan fenolik (Tabel 1). Hasil tersebut signifikan dengan uji fitokimia penelitian sebelumnya yaitu ekstrak air daun dan batang ubi jalar ungu. Hal ini dikarenakan pelarut air maupun etanol dapat menyari senyawa polar yang terdapat dalam ekstrak seperti flavonoid, tanin dan beberapa senyawa alkaloid [7].

Tabel 1. Hasil analisis fitokimia ekstrak etanol daun dan batang ubi jalar ungu

\begin{tabular}{llll}
\hline No & Jenis Uji Kualitatif & Hasil & Keterangan \\
\hline 1. & Senyawa alkaloid & + & Wagner: Endapan coklat kemerahan \\
2. & Senyawa saponin & + & Dikocok terbentuk buih \\
3. & Senyawa flavonoid & + & $\mathrm{NaOH}:$ Perubahan warna kuning \\
4. & Senyawa tanin dan fenolik & + & $\mathrm{FeCl}_{3}:$ Perubahan warna hijau kehitaman \\
\hline
\end{tabular}


Dalam penelitian ini, menggunakan subyek penelitian hewan yaitu tikus jantan galur Wistar.Sebelum penelitian, dilakukan pemeriksaan rancangan penelitian terhadap perlakuan hewan uji yang digunakan sebagai subyek penelitian antidiabetes dengan pemberian ekstrak daun ubi jalar ungu oleh Komite Etika Penelitian Kesehatan (KEPK) FK UMS. Berdasarkan surat kelaikan etik dengan nomor 313/A.1/KEPK-FKUMS/VIII/2016 menyatakan bahwa penelitian dengan ubi jalar sebagai antidiabetes dinyatakan lolos kode etik sesuai dengan Pedoman nasional etik penelitian kesehatan Departemen Kesehatan RI 2004 dan deklarasi Helsinki 1975.

Berdasarkan hasil pemantauan, setelah induksi aloksan tikus menjadi diabetes. Hal ini disebabkan karena aloksan dapat menyebabkan kerusakan sel $\beta$ pankreas dengan cara menghasilkan oksigen reaktif dari proses reduksi aloksan membentuk asam dialurat. Selanjutnya, asam dialurat tersebut mengalami reoksidasi sehingga terjadi peningkatan radikal superoksida. Hal tersebut menyebabkan dismutasi dan berubah menjadi hidrogen peroksida $\left(\mathrm{H}_{2} \mathrm{O}_{2}\right)$ lalu menghasilkan radikal hidroksil yang aktif merusak sel beta pankreas [8]. Setelah diketahui tikus sudah diabetesdiberi perlakuan ekstrak.

Pemberian ekstrak dengan 3 tingkatan dosis yang berbeda yaitu $150 \mathrm{mg} / \mathrm{kgBB}, 300 \mathrm{mg} / \mathrm{kgBB}$, dan $600 \mathrm{mg} / \mathrm{kgBB}$ diberikan satu kali sehari peroral selama 14 hari. Penggunaan ketiga besaran dosis ekstrak berdasarkan penelitian pada ekstrak air daun ubi jalar ungu yang dilakukan oleh [9]. Selain itu, dilakukan perlakuan terhadap kontrol negatif dengan akuades secara peroral satu kali sehari pada tikus diabetes selanjutnya dilakukan pemantauan kadar selama 14 hari diperoleh penurunan kadar glukosa darah dosis ekstrak $150 \mathrm{mg} / \mathrm{kgBB}$ sebesar 65,59\%, dosis ekstrak $300 \mathrm{mg} / \mathrm{kgBB}$ sebesar 71,34 \%, dan dosis ekstrak $600 \mathrm{mg} / \mathrm{kgBB}$ sebesar 46,83\%. Penurunan kadar glukosa darah kontrol negatif, kontrol positif, dan ketiga perlakuan dosis ektrak dapat dilihat pada Tabel 2.

Kontrol negatif digunakan untuk membuktikan bahwa tidak ada pengaruh penurunan kadar gula darah terhadap pemberian akuades. Kelompok kontrol negatif dengan kelompok perlakuan lain mempunyai perbedaan yang bermakna dengan nilai $\mathrm{p}<0,05$ karena penurunankadar gula darah yang terjadi tidak dari pemberian akuades. Rata-rata gula darah setelah pemberian 14 hari terjadi penurunan kadar namun tikus masih dalam keadaan diabetes setelah perlakuan selama 14 hari dengan $\mathrm{kadar}>200 \mathrm{mg} / \mathrm{dL}$ (Tabel 2). Hal ini terjadi karena mulai terjadinya regenerasi sel $\beta$ pankreas secara perlahan karenaaloksan yang digunakan sebagai penginduksi bersifat reversibel dan tidak stabil sehinggatanpa diberi intervensi kadar gula darah kelompok kontrol negatif juga mengalami penurunan.Kadar gula darah yang tinggi selama 14 hariperlakuan menandakan telah terjadi kerusakan permanen pada sel $\beta$ pankreas, sehingga pankreas tidak mampu memproduksi cukup insulin.

Tabel 2. Data kadar gula darah selama 14 hari perlakuan

\begin{tabular}{|c|c|c|c|c|}
\hline \multirow[t]{2}{*}{ Kelompok } & \multicolumn{3}{|c|}{ Kadar Glukosa Darah ( Mean \pm SD) } & \multirow[b]{2}{*}{$\begin{array}{c}\text { Selisih kadar hari ke-14 dengan } \\
\text { hari ke- } 4 \text { post aloksan }\end{array}$} \\
\hline & Kadar glukosa Awal & Hari ke-4 Post Aloksan & $\begin{array}{c}\text { Setelah } 14 \text { hari } \\
\text { perlakuan }\end{array}$ & \\
\hline Kontrol negatif & $100,33 \pm 7,76$ & $594,00 \pm 42,33$ & $288,33 \pm 52,94$ & $305,67 \pm 71,45$ \\
\hline Kontrol positif & $104,33 \pm 10,69$ & $230,67 \pm 16,77$ & $113,33 \pm 18,50$ & $117,33 \pm 25,89 *$ \\
\hline $\begin{array}{c}\text { Ekstrak dosis } 150 \mathrm{mg} / \mathrm{kg} \\
\text { BB }\end{array}$ & $99,67 \pm 14,36$ & $280,00 \pm 48,07$ & $96,33 \pm 4,72$ & $183,67 \pm 51,78 * \#$ \\
\hline $\begin{array}{c}\text { Ekstrak dosis } 300 \mathrm{mg} / \mathrm{kg} \\
\text { BB }\end{array}$ & $113,33 \pm 11,93$ & $232,67 \pm 25,69$ & $66,67 \pm 16,16$ & $166 \pm 18,19 * \#$ \\
\hline $\begin{array}{c}\text { Ekstrak dosis } 600 \mathrm{mg} / \mathrm{kg} \\
\text { BB }\end{array}$ & $86,67 \pm 12,66$ & $268,33 \pm 69,03$ & $142,67 \pm 27,06$ & $125,67 \pm 42,91 * \#$ \\
\hline $\begin{array}{l}\text { Keterangan : } \\
* \text { Berbeda bermakna }(\mathrm{p}< \\
\text { \# Tidak berbeda bermakn }\end{array}$ & $\begin{array}{l}\text { engan kontrol negati } \\
\text { 05) dengan kontrol } p\end{array}$ & & & \\
\hline
\end{tabular}

Pada kelompok kontrol positif diberikan metformin $45 \mathrm{mg} / \mathrm{kgBB}$ satu kali sehari peroral pada tikus diabetes. Metformin mempunyai efek utama dapat mengurangi produksi glukosa di hati [10]. Metformin bekerja menyebabkan produksi glukosa di hati menurun, meningkatnya pengambilan glukosa pada otot rangka sehingga terjadi penurunan resistensi insulin [11]. Berdasarkan cara kerja metformin tersebut menjadi salah satu pilihan obat yang digunakan sebagai kontrol positif karena mempunyai mekanisme kerja yang hampir sama dengan cara kerja senyawa flavonoid yang terdapat padaekstrak yaitu meningkatkan sensitivitas insulin diikuti dengan meningkatnya adiponectin [12], meningkatkan aksi enzim glukokinasedi hati [13]. Perlakuan kontrol positif selama 14 hari diperoleh hasil penurunan kadar gula darah yaitu 113,33 $\pm 18,50 \mathrm{mg} / \mathrm{dL}$. Hasil tersebut masuk pada rentang gula darah normal yaitu $50-135 \mathrm{mg} / \mathrm{dL}$ [4].

Berdasarkan hasil uji statistik antara dosis ekstrak $150 \mathrm{mg} / \mathrm{kgBB}, 300 \mathrm{mg} / \mathrm{kgBB}$, dan $600 \mathrm{mg} / \mathrm{kgBB}$ dibandingkan dengan kontrol positif diperoleh hasil berbeda tidak bermakna ( $p>0,05)$, artinya efek penurunan glukosa darah pada tiga seri dosis ekstrak tersebut tidak berbeda secara nyata dengan pemberian metformin. Hal ini juga dapat diartikan bahwa dosis 150 
$\mathrm{mg} / \mathrm{kgBB}, 300 \mathrm{mg} / \mathrm{kgBB}$, dan $600 \mathrm{mg} / \mathrm{kgBB}$ ekstrak etanol daun dan batang ubi jalar ungu mempunyai efek yang sebanding dari metformin dosis $45 \mathrm{mg} / \mathrm{kgBB}$.

Penurunan glukosa darah diperkirakan disebabkan karena adanya satu atau lebih senyawa yang terkandung dalam ekstrak.Dalam penelitian ini, ekstrak mengandung senyawa flavonoid, saponin, alkaloid, tanin dan fenolik.Penelitian [9], mengungkapkan hasil kualitatif senyawa dari ekstrak daun ubi jalar ungu terdiri dari flavonoid, alkaloid, saponin, dan tanin dengan hasil kuantitatif $2,16 \%, 1,81 \%, 6,21 \%$, dan 4,15\%. Hasil kuantitatif senyawa saponin dalam ekstrak $6,21 \%$ dapat dikatakan saponin memberikan pengaruh terhadap penurunan gula darah tikus. Menurut [14], saponin merupakan senyawa bioaktif terhadap diabetes. Pada penelitian ini,saponin mampu menurunkan kadar gula darah dengan mekanisme kerja sebagai antihiperglikemia dengan menstimulasi pelepasan insulin pada sel $\beta$ pankreas [13].

Ekstrak etanol daun dan batang ubi jalar ungu mengandung senyawa flavonoid dan tanin.Senyawa tersebut mempunyai efek antidiabetes.Hal ini sesuaidengan penelitian [15] bahwa senyawa flavonoid dan tanin sebagai agen utama dari ekstrak daun ubi jalar ungu dalam menurunkan kadar gula darah. Menurut penelitian [16] flavonoid dapat meningkatkan utilisasi glukosa di jaringan perifer. Selain itu, senyawa ini dapat meningkatkan aksi enzim glukokinasedi hati [12].

Berdasarkan penelitian [17] dilaporkan senyawaquersetin merupakan salah satu golongan flavonoid yang memiliki kemampuan antidibetika. Senyawa quercertin diketahui dapat meregenerasi sel pankreas dan menstimulasi pelepasan insulin serta meningkatkan pengambilan $\mathrm{Ca}^{2+}$ dari sel islet pankreas. Dengan ini maka senyawaquersetin termasuk golongan senyawa flavonoid yang dapat menurunkan gula darah pada tikus dalam keadaan diabetes. Senyawa golongan flavonoid lain yang diperkirakan mempunyai efek antidiabetes adalah antosianin. Berdasarkan penelitian yang dilakukan oleh [12], antosianin dapat meningkatkan pelepasan adiponektin yang dapat meningkatkan sensitivitas insulin. Aksi senyawa tersebut menunjukkan bahwaantosianin berpotensi sebagai agen antidiabetes.

Golongan senyawa tanin pada ekstrak ikut berperan dalam menurunkan kadar glukosa darah diduga karena adanya antioksidan yang merupakan senyawa antioksidan alami pada tumbuhan yang dapat menghambat radikal bebas sehingga dapat mengurangi resistensi insulin [18]. Berdasarkan penelitian [19], tanin dapat meningkatkan pengambilan glukosa dengan translokasi GLUT-4 dengan memodulasi sinyal insulin melalui jalur PI3K. Aksi tanintersebut menunjukkan bahwa flavonoid mempunyai pengaruh terhadap penurunan kadar glukosa dalam penelitian ini.

\section{KESIMPULAN}

Berdasarkan hasil penelitian dan analisis data yang telah dilakukan dapat disimpulkan 1) ekstrak etanol daun dan batang ubi jalar ungu dengan pemberian dosis 150, 300, dan $600 \mathrm{mg} / \mathrm{kgBB}$ dapat memberikan efek menurunkan kadar glukosa darah berturut -turut menjadi 65,59;71,34; dan 46,83\% pada tikus jantan galur Wistar yang diinduksi aloksan setelah perlakuan 14 hari.

Ekstrak etanol daun dan batang ubi jalar ungu mengandung golongan senyawa alkaloid, flavonoid, saponin, tanin dan senyawa fenolik.

\section{UCAPAN TERIMA KASIH}

Penulis mengucapkan terima kasih kepada Laboratorium Kimia Farmasi dan Farmakologi Fakultas farmasi Universitas Muhammadiyah Surakarta yang telah membantu penulis dalam menyelesaikan penelitian ini.

\section{Daftar Pustaka}

[1] IDF, 2015, IDF Diabetes Atlas, 7th ed, International Disbetes Federation, USA

[2] Mendosa B.D., 2008, Revised International Table of Glycemic Index ( GI ) and Glycemic Load ( GL )

[3] Ginting E., Utomo J.S. and Yulifianti R., 2011, Potensi Ubi jalar Ungu sebagai Pangan Fungsional, , 6(1).

[4] Johnson-Delaney C., ABVP-Avian, Capello V. and Lennox A., 2008, Excotic Companion Medicine Handbook For Veterinarians, Dalam Eastside Avian and Exotic Animal Medical Center, p. 19

[5] Krishnaveni, Marimuthu and Ravi Dhanalaksmi, 2014, qualitative and quantitative Study of Phytochemicals in Muntingia calabura L. Leaf and Fruit, World Journal of Pharmaceutical Research, 3(6), 1687-1696.

[6] Surjowardojo P., Thohari I. and Ridhowi A., 2014, Quantitative and Qualitative Phytochemicals Analysis of Muntingia calabura, Journal of Biology, Agriculture and Healthcare, 4 (16), 84-89.

[7] Sarker S.D., Latif Z. and Gray A., 2006, Natural Products Isolation,Methods in Biotechnology, 325.

[8] Nugroho A.E., 2006, Review Hewan Percobaan Diabetes Mellitus : Patologi Dan Mekanisme Aksi Diabetogenik, 7, 378-382.

[9] Ijaola T.O., Osunkiyesi A.A., Taiwo A.A., Oseni O.A. and Ajayi J.O.R.T., 2014, Antidiabetic Effect of Ipomoea Batatas in Normal and AlloxanInduced Diabetic Rats Abstract: 7 (5), 16-25.

[10] Perkeni, 2011, Konsensus Pengendalian danPencegahan Diabetes Melitus Tipe 2 di Indonesia 2011, Perkeni, 78.

[11] Rang H, Dale M. and Ritter J, 2011, Rang and Dale's Pharmacology 7th edition.

[12] Ghosh D. and Konishi T., 2007, Anthocyanins and anthocyanin-rich extracts: role in diabetes and eye function, $200-208$.

[13] Bhushan, RAO C., OJHA S., Vijayakumar M. and Verma A., 2010, An analytical review of plants for anti diabetic activity with their,1, (1), 29-46.

[14] Deokate U.A. and Khadabadi S., 2012, Pharmacology and Phytochemistry of Coccinia Indica, An International Research Journal, 3 (3), $179-185$.

[15] Asriyanti V., Bangsawan P.I. and Hadi D.P., 2013, Hypoglycemic Effect Test of Sweet Potato Leaves Ethanol Extract Againts Blood Glucose Level of Alloxan-Induced White Male Wista Rat.

[16] Brahmachari G., 2011,6. Bio-flavonoids with promising anti- diabetic potentials : A critical survey, Challenge and Scope of Natural Product in Medical Chemistry, 661 (2), 187-212.

[17] Tapas A.R., Sakarkar D.M. and Kakde R.B., 2008, Flavonoids as Nutraceuticals: A Review, , 7, 1089-1099.

[18] Haryoto, Nurhardianti N., Sujono T.A., Suhendi A. and Muhtadi, 2016, Antidiabetes Mellitus Ekstrak Etanol Kulit Batang Tumbuhan Sala (Cyanometra ramiflora L.) Terhadap Tikus Jantan

[19] Galur Wistar yang Diinduksi Aloksan, Universty Research Colloquium, (2013), 113-122.

[20] Kumari M. and Jain S., 2012, Tannins: An Antinutrient with Positive Effect to Manage Diabetes, 1 (12), $70-73$. 